\title{
METODOLOGIA SENAI DE EDUCAÇÃO PROFISSIONAL APLICADA A EDUCAÇÃO A DISTÂNCIA
}

\author{
GOIÂNIA/GO AGOSTO/2018
}

\author{
Letícia de Oliveira Santos Pereira - SENAI GO - leticia.senai@sistemafieg.org.br \\ Fabrício Leandro Costa e Silva - SENAI GO - fabriciosilva.senai@sistemafieg.org.br
}

Tipo: Relato de Experiência Inovadora (EI)

Categoria: Métodos e Tecnologias

Setor Educacional: EDUCAÇÃO MÉDIA E TECNOLÓGICA

\begin{abstract}
RESUMO
Este artigo faz discussões sobre a utilização da Metodologia SENAl de Educação Profissional na Educação a Distância. Em face disso, no primeiro momento discorre sobre os impactos das mudanças ocorridas no mundo do trabalho e na educação profissional. No segundo momento, apresenta o que é a metodologia SENAI de Educação Profissional e como ela é aplicada a educação a distância. É importante salientar que o docente ganha destaque neste artigo, pois esse profissional é o principal responsável pela eficácia na aplicação dessa metodologia nos cursos de educação a distância. Em um momento histórico marcado pelas mudanças nos processos produtivos, o Serviço Nacional de Aprendizagem Industrial apresenta uma metodologia de formação para as competências demandadas pelo mundo do trabalho e amplia o acesso à educação profissional através de um modelo de educação flexível, mais conhecido como Educação a Distância.
\end{abstract}

Palavras-chave: Metodologia SENAI; Educação Profissional; Educação a Distância; Atuação Docente. 


\section{Introdução}

As recentes mudanças no cenário socioeconômico brasileiro apresentam novos desafios para a educação profissional. Se anteriormente o mundo do trabalho demandava profissionais com conhecimentos técnicos e capacidade de cumprir as tarefas exigidas com disciplina e obediência, hoje o mercado busca profissionais capazes de assumir responsabilidades, que possuam iniciativa, autonomia e responsabilidade social.

A diferenciação desse perfil profissional sucedeu em decorrência da mudança do modelo de produção que passou de uma organização do trabalho centrada na separação entre concepção e execução, no modelo taylorista-fordista, para um modelo caracterizado por uma produção mais flexível, reconhecido como toyotista.

Em 1992 o Sistema Toyota de Produção (STP) foi julgado pelo Massachussetts Institute of Technology (MIT) como sendo "um tipo ideal transnacional de produção moderna", por ser: "flexível e enxuto"; adequável à revolução tecnológica vigente (microeletrônica e tecnologias de informações de base microeletrônica) e às transformações nas relações fornecedores-empresas-clientes MARKERT, 1994, p. 369).

Essa mudança no cenário econômico impulsionou grandes reformas educacionais, que de acordo com Deluiz (2001), iniciaram no Brasil a partir da década de 90 como parte de um conjunto de reformas estruturais do Estado, decorrentes do ajuste macroeconômico do país que visava a superação da inflação e estagnação e retomada do crescimento econômico.

Como resposta a todo esse processo as empresas passaram a valorizar cada vez mais as competências profissionais e a exigir trabalhadores capacitados para resolver problemas complexos com base nos seus conhecimentos e habilidades.

Da mesma forma e ritmo, ou seja, em plena ascensão, a Educação a Distância apresenta um cenário distinto em meio ao processo de ensino e aprendizagem utilizando estratégias de interação e construção do conhecimento inovadoras e colaborativas e ampliando o acesso à educação e capacitação profissional.

O Decreto ํํ 9.057 de 25 de maio de 2017 apresenta o conceito de educação à distância:

Art. 1ㅇ Para os fins deste Decreto considera-se educação a distância a modalidade educacional na qual a mediação didático-pedagógica nos processos de ensino e aprendizagem ocorra com a utilização de meios $e$ tecnologias de informação e comunicação, com pessoal qualificado, com políticas de acesso, com acompanhamento e avaliação compatíveis, entre outros, e desenvolva atividades educativas por estudantes e 
profissionais da educação que estejam em lugares e tempos diversos.

De acordo com esse conceito apresentado, a educação a distância determina uma mudança de postura aos docentes, que devem se adequar a esse modelo de formação mais flexível e buscar estratégias compatíveis com essa realidade. Os alunos que também devem possuir um perfil ativo e responsável em meio a esse contexto educacional.

Neste cenário de mudanças no sistema produtivo e educacional, o Serviço Nacional de Aprendizagem Industrial - SENAI buscou fundamentar sua prática formativa no desenvolvimento das competências requeridas pelo mundo do trabalho.

Trataremos agora sobre essa metodologia formativa adotada pelo Serviço Nacional de Aprendizagem Industrial, denominada de Metodologia SENAI de Educação Profissional, com foco em entender sua aplicação na Educação a Distância.

\section{Desenvolvimento}

Conforme apresentado anteriormente, o SENAI tem como objetivo do seu processo formativo o desenvolvimento de competências correspondentes às ocupações requeridas pelos segmentos industriais que fazem parte do seu escopo de atendimento.

De acordo com Fleury e Fleury (2001) "competência é uma palavra do senso comum, utilizada para designar uma pessoa qualificada para realizar alguma coisa". Os autores vão além e apontam que o oposto disso não é apenas a negação desta capacidade, mas chega a sinalizar um sentimento pejorativo em relação a essa desqualificação. Já Perrenoud (1991) define competência como capacidade de agir eficazmente em um determinado tipo de situação, apoiada em conhecimentos, mas sem limitar-se a eles.

Baseando-se nessas e em outras definições o SENAI compreende competência profissional como uma mobilização de conhecimentos, habilidades e atitudes necessários ao desempenho de funções e atividades típicas de uma Ocupação, segundo padrões de qualidade e produtividade requeridos pela natureza do trabalho.[1]

A escolha de quais competências serão desenvolvidas a partir dos cursos ofertados pelo SENAI é feita através da elaboração de um perfil profissional que descreve o que é idealmente necessário que um trabalhador seja capaz de realizar em uma determinada ocupação. No SENAI esse perfil profissional é construído por um comitê de especialistas, denominado de Comitê Técnico Setorial. 
Diversos especialistas que representam o Serviço Nacional de Aprendizagem Industrial, as empresas, os sindicatos, as associações e ou órgãos de classe, o meio acadêmico e o poder público compõem os comitês técnicos setoriais. Essa é a primeira etapa para a construção dos cursos que farão parte do portfólio do SENAI, a próxima fase é a construção do Desenho Curricular.

Os Desenhos Curriculares são os resultados do processo de concepção de ofertas formativas que devem propiciar o desenvolvimento das capacidades referentes às competências de um perfil profissional.[2] Baseando-se no desenho curricular que os planos de cursos são elaborados. "O plano de curso é a sistematização da proposta geral de trabalho do professor naquela determinada disciplina ou área de estudo. (VASCONCELLOS, 1995, p.117 in Padilha, 2003, p.41). Esse documento deve nortear toda a prática docente.

Após entendermos como é realizado o planejamento dos cursos ofertados pelo Serviço Nacional de Aprendizagem Industrial - SENAI, vamos abordar o papel do docente nesse processo, passando por todas as etapas da atuação desse profissional, com foco principal nos docentes que exercem suas atividades nos cursos de educação a distância.

Visando uma prática docente adequada a metodologia proposta, o SENAI também buscou descrever o papel desse profissional na instituição e forneceu orientações para uma prática eficaz. Assim, para o SENAI o docente deve ter como principal objetivo a formação para as competências, sendo necessário então, romper com alguns conceitos e práticas educacionais tradicionais.

A principal mudança nesse cenário é em relação aos papeis de aluno e docente. Se anteriormente $o$ docente era $o$ detentor do conhecimento e sua principal responsabilidade era transmiti-los aos educandos, na metodologia SENAI ele assume o papel de protagonista no processo de ensino e mediador no processo de aprendizagem. Já o aluno que anteriormente deveria se comportar passivamente nesse processo, agora deve se comportar como protagonista no processo de aprendizagem.

Nesse sentido, a atuação docente deve deslocar o foco do ensinar para o aprender e objetivar a formação de pessoas autônomas e capazes de resolver problemas complexos mobilizando os seus conhecimentos, habilidades e atitudes.

Os docentes que atuam na educação a distância do SENAI, além de se preocupar em buscar estratégias para formar para as competências, precisa também buscar 
metodologias que se adequem a esse modelo de educação flexível. Para que isso ocorra é necessário ter clareza de que a tecnologia por si só não é capaz de promover educação e que para que o processo de ensino e aprendizagem se torne eficaz é preciso levar em consideração as especificidades da educação a distância.

Para Oliveira (2003, p. 94):

\begin{abstract}
Ao avaliar a contribuição das tecnologias para a educação, duas atitudes radicais parecem ser desfavoráveis: a) supor que qualquer incorporação de tecnologia basta para produzir mudanças; b) criticar sem medida a sua incorporação. Desta forma, há os que elogiam a tecnologia, sem considerar seus riscos e limitações e há os que a criticam, sem resgatar aspectos positivos.
\end{abstract}

A qualidade de um curso a distância não depende apenas do material que é disponibilizado para o estudo do aluno, mas sim das estratégias que o docente utilizará para conduzir o processo de ensino, promover interação e avaliar os resultados.

Buscando realizar uma educação de qualidade o SENAI orienta os seus docentes sobre a formação para as competências e sobre a atuação na educação a distância. Essas orientações são realizadas através de diversos documentos, cursos de capacitação profissional e equipe de coordenação capacitada para conseguir orientar e auxiliar os docentes no cumprimento de suas atividades.

Sendo assim, para obter êxito os docentes devem se apropriar das orientações fornecidas pela instituição e elaborar um planejamento minucioso do processo de ensino e aprendizagem. Como orientação para esse planejamento o SENAI desenvolveu um fluxo das ações docentes, que comtemplam as seguintes fases:

Figura 1 Planejamento e Desenvolvimento dos processos de Ensino e Aprendizagem 


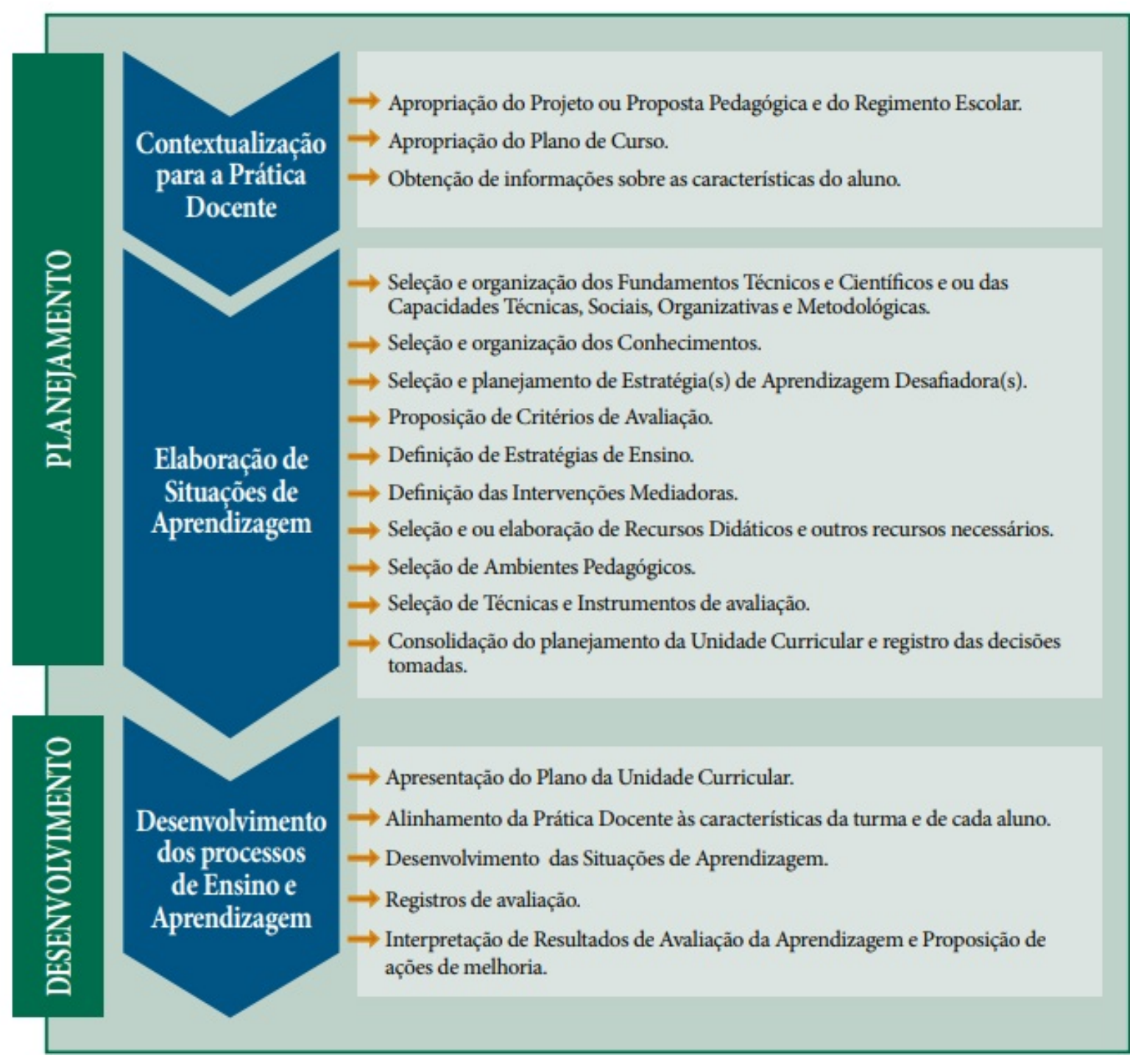

Fonte: Metodologia SENAI de Educação Profissional SENAI/DN2013

Conforme as etapas do planejamento descritas na figura acima, após a fase de contextualização da prática docente, o educador deve começar a etapa de elaboração das Situações de Aprendizagem.

As situações de aprendizagem, nesta Metodologia, são caracterizadas pelo conjunto de ações que norteiam a atuação docente e favorecem a aprendizagem significativa. Para elaboração dessas situações de aprendizagem o docente deve selecionar e organizar os fundamentos técnicos e científicos e ou as capacidades técnicas, sociais, organizativas e metodológicas e organizar os conhecimentos a serem trabalhados.

Após essa seleção e organização o docente deve definir a sua estratégia de Aprendizagem Desafiadora incluindo além das habilidades técnicas exigidas para o exercício de uma atividade padrão, um conjunto de comportamentos sociais, organizativos e metodológicos, tais como: tomada de decisão, comunicação ativa e 
organização das tarefas.

Esses comportamentos são evidenciados no momento em que desafios são propostos, ou seja, uma atividade nova instigando o aluno a buscar novos caminhos, soluções e ideias. Ressalto que o produto deste esforço, não necessariamente tem a obrigação de ser inédito. Mas, sim, ser resultado de análise, tomada de decisão e da realização de uma ou mais atividade, onde não há resposta pronta que pode ser fisgada.

Um desafio deve desequilibrar o aluno, levando-o a buscar soluções inusitadas e novos conhecimentos (Perrenoud, 1999). Logo, o estabelecimento de parâmetros devem servir como objeto de validação da competência definida e/ou esperada do aluno.

Após essa seleção dos desafios e da proposição dos critérios de avaliação é necessário pensar nas estratégias de ensino que serão adotadas. Essas estratégias precisam levar em consideração que o aluno não estará, na maior parte do seu tempo de estudos, no mesmo tempo e espaço que o docente. Nesse sentido, deve se buscar estratégias que facilitem a aprendizagem e que sejam capaz de motivar os alunos, evitando assim a evasão.

Para que esse processo seja eficaz o docente precisa não apenas ensinar, mas também mediar o processo de aprendizagem. As estratégias de intervenção mediadora também precisam ser planejadas e levar em consideração as especificidades da educação a distância. Os alunos desse modelo de educação tendem a sentir falta da relação entre docente e aluno. Assim, uma estratégia mal planejada pode acarretar em evasão.

De acordo com Comarella, 2009:

\footnotetext{
A principal diferença entre a educação presencial e a EaD é o canal de comunicação em que ocorre a interação entre o professor e o estudante. Em ambas as modalidades o professor provoca o aprendizado, estimula 0 estudante. Entretanto, na EaD, as intervenções do professor são mediadas por algum tipo de tecnologia.
}

O fato da tecnologia estar presente nessa relação, envolve a necessidade de se pensar em estratégias que minimizem o impacto da ausência física do docente. Assim, intervenções que geram o sentimento de competência nos alunos tornam-se muito importantes.

Após todas essas etapas o docente precisa definir os recursos didáticos, os ambientes pedagógicos e os instrumentos de avaliação que serão utilizados. A consolidação dessas informações em um documento é a última etapa da ação de planejamento do docente e dando início então ao desenvolvimento dos processos de ensino e 
aprendizagem planejados.

\section{Considerações finais}

Este artigo procurou fazer uma análise sobre a utilização da metodologia SENAI de educação profissional na educação a distância. Buscamos também, apresentar a importância da atuação docente para obtenção de êxito nesse processo.

Em face disso, tratamos sobre as mudanças ocorridas no mundo do trabalho e como elas contribuíram para as novas exigências profissionais que consequentemente acarretaram em mudanças na educação, sobretudo, na educação profissional.

Apresentamos o modelo de atuação do SENAI, desde a concepção dos cursos até o planejamento e desenvolvimento dos processos de ensino e aprendizagem nos cursos de educação a distância.

Concluímos que a atuação do docente na educação a distância deve ser diferente da educação presencial, pois o modelo de educação flexível exige estratégias diversificadas e compatíveis com as especificidades da educação a distância. É necessário ressaltar que ainda com a adoção dessas estratégias diversificas é possível formar para as competências e adotar a Metodologia SENAI de Educação Profissional como referencial no desenvolvimento de todo o processo formativo.

\section{Referências}

BRASIL $^{a}$. Decreto $n^{\circ}$ 9.057, de 25 de maio de 2017. Regulamenta o art. 80 da Lei no 9.394, de 20 de dezembro de 1996, que estabelece as diretrizes e bases da educação nacional. Diário Oficial da União, Brasília, 20 dez. 2005. Disponível em: Acesso em: 27 jun. 2018.

COMARELLA, R. L. Educação Superior a Distância: Evasão discente. Dissertação de Mestrado, Universidade Federal de Santa Catarina, Santa Catarina, 2009.

DELUIZ, N. O Modelo das competências profissionais no mundo do trabalho e na educação: implicações para o currículo. Disponível em: $<$

http://www.feis.unesp.br/Home/DSAA/DSAA/ProjetoGQTSCM/documentos/educacao/Es tagio\%2520Comp.Profissionais.pdf> Acesso em 27 jun.2018. 
FLEURY, Maria Tereza Leme; FLEURY, Afonso. Construindo o conceito de competência. Revista administração contemporânea, Curitiba, ed. especial, 2001.

MARKERT, Werner. 'Lean production' - uma revolução da forma de produção capitalista? A discussão alemã e internacional, sua implementação no Brasil e conseqüências para a formação profissional". In: Educação e Sociedade, 1994, nำ49, pp. 362-390 (Dezembro).

MOORE, M.; KEARSLEY, G. Distance education: a systems view. Belmont: Wadsworth Publishing Co. 1996.

NUNES, Vanessa Battestin. O papel do tutor na educação a distância: como tem sido concebido pelas instituições de ensino? Serra - ES - 2013.

OLIVEIRA, Mariza da Gama Leite de. A capacitação do professor para o uso das tecnologias da informação e comunicação. 2003. Disponível em: Acesso em: 27 jun. 2018.

PADILHA, Paulo Roberto. Planejamento dialógico: como construir o projeto políticopedagógico da escola. 4ª Ed. São Paulo: Cortez, 2003.

SENAI. Departamento Nacional. Metodologia SENAI de educação profissional. Brasília: SENAI/DN, 2013.

[1] Serviço Nacional de Aprendizagem Industrial. Departamento Nacional. Metodologia SENAI de Educação Profissional. 1. Ed. Brasília: 2013.

[2] Serviço Nacional de Aprendizagem Industrial. Departamento Nacional. Metodologia SENAI de Educação Profissional. 1. Ed. Brasília: 2013. 